\title{
Characterization of carbon nanofiber (CNF)/polymer composite coated on cotton fabrics prepared with various circuit patterns
}

Hyelim Kim ${ }^{1}$ and Sunhee Lee 2* $^{*}$

*Correspondence:
shlee014@dau.ac.kr
${ }^{2}$ Department of Fashion
Design, Dong-A University,
Busan 49315, Republic
of Korea
Full list of author information
is available at the end of the
article

${ }^{*}$ Correspondence: shlee014@dau.ac.kr Design, Dong-A University, Busan 49315, Republic

\begin{abstract}
Fabric heating elements with carbon nanofiber (CNF)/Poly(vinylidene fluoride-cohexafluoropropylene) (PVDF-HFP) composite coated cotton fabrics were prepared with various circuit patterns with the aim of providing more flexible and uniform heating performance compared to conventional fabric heating elements. To investigate the properties of the fabric heating element according to the pattern condition, patterns consisting of 3, 5, and 7 horizontal lines, i.e., P3, P5 and P7, were respectively used; and subsequently, vertical lines were added to the horizontal lines, i.e., 2P3, 2P5 and 2P7, respectively. P0 was used as the referencesample. P0 showed a surface resistance of $1.2 \times 10^{3} \Omega / \mathrm{sq}$ at a current of $0.85 \mathrm{~A}$ and an electric heating temperature of $76.9^{\circ} \mathrm{C}$. P3 and $2 \mathrm{P} 3$ showed better electrical and electric heating properties than other samples, showing surface resistance values of $1.0 \times 10^{3}$ and $1.2 \times 10^{3} \Omega / \mathrm{sq}$ at the current values of 0.20 and $0.25 \mathrm{~A}$, and surface temperatures of 71.8 and $75.7^{\circ} \mathrm{C}$, respectively. Although the currents applied to $\mathrm{P} 3$ and $2 \mathrm{P} 3$ were lower than that applied to P0, the electrical heating properties were modified to be similar. In terms of mechanical properties and water repellency, it was shown that the coated fabrics had higher values compared to the uncoated fabric. It was thus suggested that a small amount of CNF/PVDF-HFP composite can be used to manufacture an electric heating element with excellent performance.
\end{abstract}

Keywords: Carbon nanocomposite, Carbon nanofiber (CNF), Poly(vinylidene fluorideco-hexafluoropropylene) (PVDF-HFP), Circuit patterns, Fabric heating element

\section{Introduction}

Recently, e-textiles have been receiving significant interest in terms of their applicability to wearable smart devices, because textiles are breathable, flexible and lightweight, yet strong and robust (Åkerfeldt et al. 2014; Asghar et al. 2016). Wearable smart devices incorporating e-textiles are used in healthcare, sports, military, wearable displays, biomonitoring and power storage devices and so on. For these various applications, efforts are continuing to integrate functional nanomaterials with common textiles to provide flexible, lightweight materials and to improve electrical properties. The fabric heating element is one of the application fields of e-textiles used for the maintenance of body temperature such as work clothes used in extreme environments, protective clothing, military, immersion suit for winter season, etc. Preparation methods for heating

(c) The Author(s) 2018. This article is distributed under the terms of the Creative Commons Attribution 4.0 International License (http://creativecommons.org/licenses/by/4.0/), which permits unrestricted use, distribution, and reproduction in any medium, provided you give appropriate credit to the original author(s) and the source, provide a link to the Creative Commons license, and indicate if changes were made. 
elements include methods for making a fiber or fabric (Ilanchezhiyan et al. 2015; Park and Lee 2015; Roh and Kim 2016), forming a film (Jee et al. 2013; Park et al. 2015; Wang et al. 2015; Wang and Ruan 2016) and coating fabric (Kang and Lee 2015; Pahalagedara et al. 2017; Tian et al. 2016).

A number of studies on the preparation of electric heating elements using conductive nanocomposites have also been carried out. Such materials have electrical conductivity based on the types of the functional composites, like metal particles such as silver (Ag) (Stempien et al. 2016; Wang et al. 2016b), and copper (Cu) (Roh and Kim 2016; Wang and Ruan 2016), and conductive polymers such as polyaniline (Wang et al. 2015), and polypyrrole (Wang et al. 2016a). Research of conductive nanocomposites based on carbon nanomaterials has being actively pursued with the aim of improving flexibility and reducing weight. Carbon nanocomposites are high-performance carbon-based materials in which carbon fiber (Park and Lee 2015), graphite (Jee et al. 2013; Park et al. 2015), carbon nanotube (CNT) (Cipriano et al. 2008; Ilanchezhiyan et al. 2015; Jee et al. 2013), and carbon nanofiber (CNF) (Lee 2011, 2012; Das et al. 2012; Kang and Lee 2015) are charged in the polymer. CNF is a carbon-based material that has chemical stability, thermal stability and facilitates ease of handling like distribution. In addition, due to their availability in large quantities with a consistent quality, their cost is significantly lower than that of carbon nanotubes (Al-Saleh and Sundararaj 2009).

In a previous study, the electrical properties of nonwoven (Lee 2011) and silk fabric (Lee 2012) coated with CNF/PVDF-HFP composites were reported. This study found that the electrical properties of CNF/PVDF-HFP coated nonwoven fabrics increased with increasing CNFs content, and of silk fabric increased with $4 \%$ CNFs content. As well, Kang and Lee (2015) reported that in a preparation of carbon nanofiber compositecoated nylon fabric heating elements, surface temperatures of $16 \mathrm{wt} \%$ carbon nanofiber composite-coated fabrics reached $80{ }^{\circ} \mathrm{C}$ when $20 \mathrm{~V}$ was applied. When coating the entire surface, the coating solution was used in a large amount, but the problem of heating only in the localized region was confirmed. Therefore, the purpose of this study was to fabricate a fabric heating element coated with a carbon nanocomposite with various linear circuit patterns in order to resolve the economic and localized electric heating characteristics by using a smaller amount of carbon nanocomposite than the conventional planar heating element. To achieve this goal, we prepared a CNF/PVDF-HFP composite with electric heating properties, and the carbon nanocomposite was coated onto cotton fabric designed with two types of circuit patterns developed in our laboratory. The samples with various circuit patterns were analyzed by considering surface morphology, electrical property, electrical heating property, mechanical property, and water repellent property.

\section{Methods}

Materials

Carbon nanofiber (CNF) was obtained from PR-24-XT-LHT (Pyrograf III Carbon nanofiber, Pyrograf Products, Inc., USA). The Poly(vinylidene fluoride-co-hexafluoropropylene) (PVDF-HFP) chip was supplied by Solvay (SOLEF 21508, Solvay Co., Ltd.). The density was $1.78 \mathrm{~g} / \mathrm{cm}^{3}$. Acetone (1st grade, Junsei chemical Co., Ltd., Japan) was used as the solvent. The fabric used was cotton (Sombe Co., Ltd., Korea) with a 
thickness of $0.28 \mathrm{~mm}$, and a weight of $117 \mathrm{~g} / \mathrm{m}^{2}$. The size of the prepared samples was $10 \mathrm{~cm} \times 10 \mathrm{~cm}$.

\section{Preparation of CNF/PVDF-HFP composite solution}

For the obtained CNF/PVDF composite solutions, a $15 \mathrm{wt} \%$ PVDF-HFP solution was prepared in acetone and the content of CNF in the PVDF-HFP solution was $16 \mathrm{wt} \%$. The prepared CNF/PVDF composite solutions were stirred for over 1 week with a hotplate stirrer digital control (MSH-20D, Daihan Scientific, Korea), digital orbital shaker (SHO1D, Daihan Scientific, Korea) and dispersed for $24 \mathrm{~h}$ at $25^{\circ} \mathrm{C}$ using power sonic (Power sonic 410, HST, Co., Ltd., Korea).

\section{Preparation of CNF/PVDF-HFP composite coated on cotton fabrics with various circuit patterns}

Various conductive circuit patterns with CNF/PVDF composite coated on textiles were obtained through a knife-edge coating method (Kang and Lee 2015). Uncoated cotton fabric had a thickness of $0.28 \mathrm{~mm}$, and the thickness of the coating with CNF/PVDFHFP solution was $0.08 \pm 0.01 \mathrm{~mm}$. The total thickness of the coated parts of the linear heating element is $0.36 \pm 0.01 \mathrm{~mm}$. As shown in Fig. 1, six different circuit patterns with the same concentration of CNF/PVDF composite solution were designed to compare heating performances: (1) one with three parallel coated lines, (2) one with five parallel coated lines, (3) one with seven parallel coated lines, (4) two with three parallel coated lines, (5) two with five parallel coated lines, (6) two with seven parallel coated lines. The sample size was $100 \mathrm{~mm} \times 100 \mathrm{~mm}$, and the coated line size was $100 \mathrm{~mm} \times 10 \mathrm{~mm}$. Weight increases of each of the circuit patterns are summarized in Table 1. After the

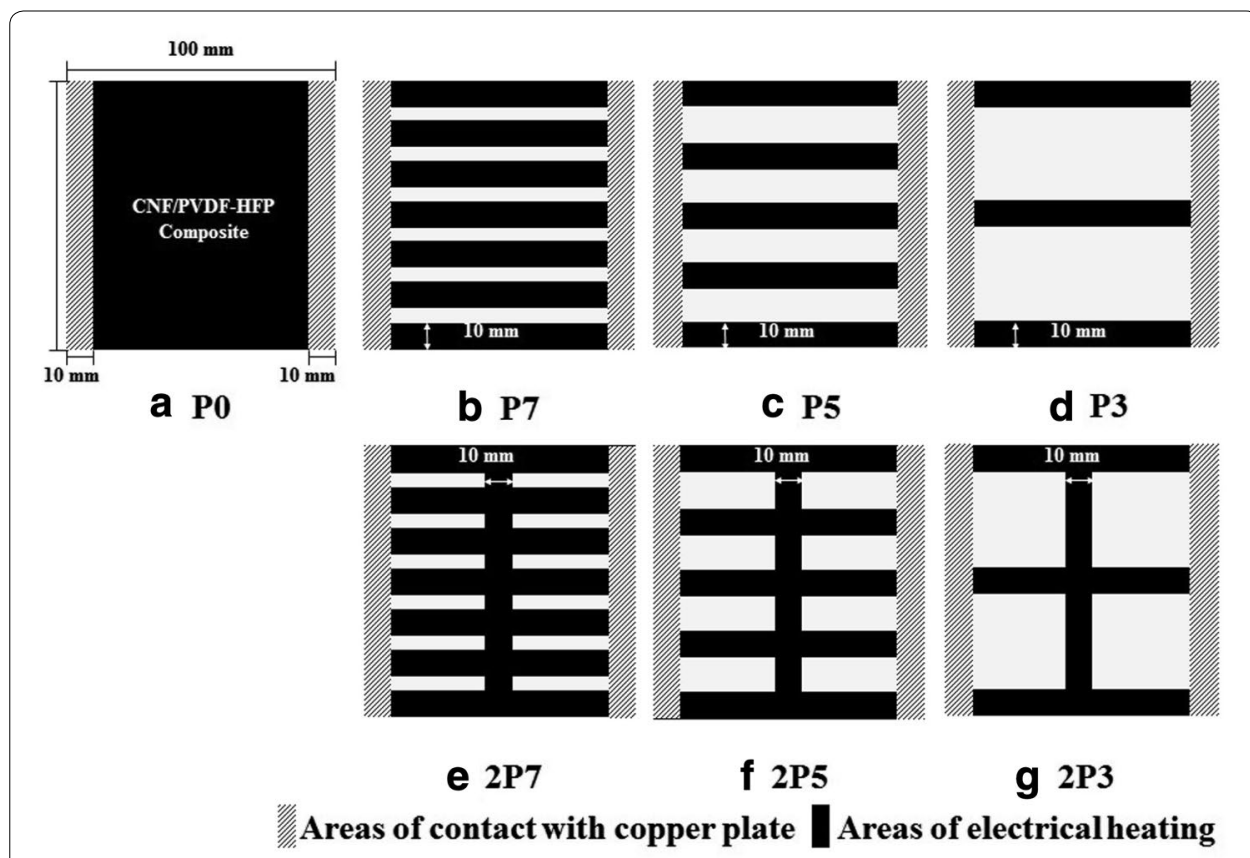

Fig. 1 Design of CNF/PVDF-HFP composite coated on cotton fabrics with various circuit patterns 
Table 1 Characteristics of CNF/PVDF-HFP composite coated on cotton fabrics of various circuit patterns

\begin{tabular}{|c|c|c|c|c|c|}
\hline \multirow{2}{*}{$\begin{array}{l}\text { Sample } \\
\text { code }\end{array}$} & \multirow{2}{*}{$\begin{array}{l}\text { Weight } \\
\text { increase (\%) }\end{array}$} & \multicolumn{2}{|c|}{ Electrical properties } & \multicolumn{2}{|c|}{ Tensile properties } \\
\hline & & $\begin{array}{l}\text { Surface } \\
\text { resistivity }(\Omega / s q)\end{array}$ & $\begin{array}{l}\text { Power-law } \\
\text { exponent values }(n)\end{array}$ & Load (N) & $\begin{array}{l}\text { Elongation } \\
(\%)\end{array}$ \\
\hline Uncoated & - & $4.22 \times 10^{11} \pm 0.16$ & - & $7.33 \pm 0.26$ & $4.76 \pm 2.83$ \\
\hline PO & 76.5 & $1.15 \times 10^{3} \pm 0.41$ & 1.06 & $10.10 \pm 0.15$ & $13.48 \pm 1.20$ \\
\hline P7 & 54.6 & $1.28 \times 10^{3} \pm 0.42$ & 1.09 & $8.31 \pm 0.09$ & $14.24 \pm 1.44$ \\
\hline P5 & 48.1 & $1.36 \times 10^{3} \pm 0.19$ & 1.08 & $8.25 \pm 0.40$ & $14.08 \pm 0.82$ \\
\hline P3 & 37.2 & $1.01 \times 10^{3} \pm 0.27$ & 1.08 & $7.98 \pm 0.15$ & $13.48 \pm 1.20$ \\
\hline $2 \mathrm{P7}$ & 60.4 & $1.21 \times 10^{3} \pm 0.47$ & 1.10 & $8.91 \pm 0.33$ & $15.28 \pm 0.24$ \\
\hline $2 \mathrm{P} 5$ & 49.0 & $1.65 \times 10^{3} \pm 0.46$ & 1.06 & $8.40 \pm 0.18$ & $15.08 \pm 0.69$ \\
\hline $2 \mathrm{P} 3$ & 40.0 & $1.17 \times 10^{3} \pm 0.73$ & 1.08 & $8.28 \pm 0.58$ & $14.86 \pm 1.07$ \\
\hline
\end{tabular}

coating, samples were stored at room temperature for $24 \mathrm{~h}$ and maintained in a desiccator before characterization.

\section{Characterization}

Surface morphology of CNF/PVDF-HFP composite coated on textiles was analyzed using a fabric image analysis system (Nex measure Pro5 NTZ-6000, Bestec Vision Co., Ltd.) at 6.5 magnification and a field emission scanning electron microscope (FE-SEM, JSM-6700F, Joel, Japan) at 200, 5000 and 10,000 magnification. The CNF/PVDF-HFP composite coated on textiles was visualized after a platinum coating process.

The electrical properties of the CNF/PVDF-HFP composite coated on textiles were measured based on surface resistivity. The surface resistivity measurements were performed using a four-probe resistivity meter (MP-8111, TMA Co., Ltd., Korea). Five samples were tested and the measured results were averaged.

The electric heating property of the CNF/PVDF-HFP composite coated on textiles was analyzed in order to investigate the heating property when a voltage was applied. The electrical heating property was measured using a heating pad clamping device (DongWoo Int. Ltd., Korea) connected to a DC power supply (CPS-2450B, CHUNGPAEMT. Co., Ltd., Korea) at an applied voltage interval of $5 \mathrm{~V}$ from $0 \mathrm{~V}$ to $20 \mathrm{~V}$ under a thermal imaging camera (FLIR i5, FLIR Systems INC, USA). We measured the current generated when a voltage was applied to the sample. Five samples were tested and three randomly selected parts of the heating area of each sample were measured. The average was obtained and then the value was used.

The mechanical properties of the CNF/PVDF-HFP composite coated on textiles were measured with a constant rate of extension machine (Autograph AGS-500D, Shimadzu Co., Ltd., Japan). The tensile strength and elongation of the CNF/PVDF-HFP composite coated on textiles with various circuit patterns were measured. The sample size was $10 \mathrm{~cm} \times 10 \mathrm{~cm}$, the clamp length was set at $50 \mathrm{~mm}$, and the test speed was $50 \mathrm{~mm} / \mathrm{min}$. Three specimens were tested to determine the mean values.

Contact angles (CA) were measured and analyzed to determine the water repellency of the CNF/PVDF-HFP composite coated on textiles. CAs were measured using a contact angle meter (Phoenix 300, SEO Co., Ltd., Korea). Liquid drops were placed on the CNF/ 
PVDF-HFP composite coated on textiles with a pipette, and the image of each drop was captured as quickly as possible after the liquid drops were deposited onto the sample surface. The average of nine measurements obtained from each sample was reported.

\section{Results and discussion}

\section{Surface morphology of CNF/PVDF-HFP composite coated on cotton fabrics with various} circuit patterns

The surface morphology of the CNF/PVDF-HFP composite coated on cotton fabric is shown in Fig. 2. At $6.5 \times$ magnification, we confirmed that the surface of samples formed



Fig. 2 Surface morphology of the CNF/PVDF-HFP composite coated on cotton fabrics 
a CNF/PVDF-HFP membrane. At 30× magnification, the CNF bundles were observed, and on closer inspection, these may have been CNF. At the $5000 \times$ and $10,000 \times$ magnifications, the samples were confirmed to have a CNF/PVDF-HFP membrane with pores and CNF. The results indicated the presence of CNF/PVDF-HFP membrane and CNF on cotton fabric.

\section{Electrical properties of CNF/PVDF-HFP composite coated on cotton fabrics with various circuit patterns}

The surface resistivity values of CNF/PVDF-HFP composite coated on cotton fabric with various circuit patterns are presented in Table 1 . In general, the characteristics and applications can be classified according to the surface resistance value of the material, with the resistivity value of $10^{1}-10^{6}$ classified as conductive materials (Al-Saleh and Sundararaj 2009).

The surface resistivity value of P0 was $1.15 \times 10^{3} \pm 0.41 \Omega /$ sq; the surface resistivity values of P7, P5, P3 were $1.28 \times 10^{3} \pm 0.42,1.36 \times 10^{3} \pm 0.19$ and $1.01 \times 10^{3} \pm 0.27 \Omega /$ sq, respectively. The surface resistivity values of $2 \mathrm{P} 7,2 \mathrm{P} 5$ and $2 \mathrm{P} 3$ added vertical circuit lines were $1.21 \times 10^{3} \pm 0.47,1.65 \times 10^{3} \pm 0.46$ and $1.17 \times 10^{3} \pm 0.73 \Omega /$ sq, respectively. The surface resistivity was $1.01 \times 10^{3}$ to $1.65 \times 10^{3} \Omega / \mathrm{sq}$, and it was confirmed that the samples with various circuit patterns exhibit excellent electrical characteristics. In terms of the number of circuit lines, the resistances of P3 and 2P3 with three lines were lower than those of fabric heaters with 5 and 7 lines, and it is shown that the effect of the resistance is less affected by the decrease in the number. By pattern, P7, P5 and P3 showed slightly lower resistance than 2P7, $2 \mathrm{P} 5$ and $2 \mathrm{P} 3$, indicating that the line in the vertical direction slightly increased the resistance.

The current-voltage (I-V) characteristics of the CNF/PVDF-HFP composite coated on cotton fabric with various circuit patterns are presented in Fig. 3. Each sample showed a tendency to have an increased current as the applied voltage increases. The

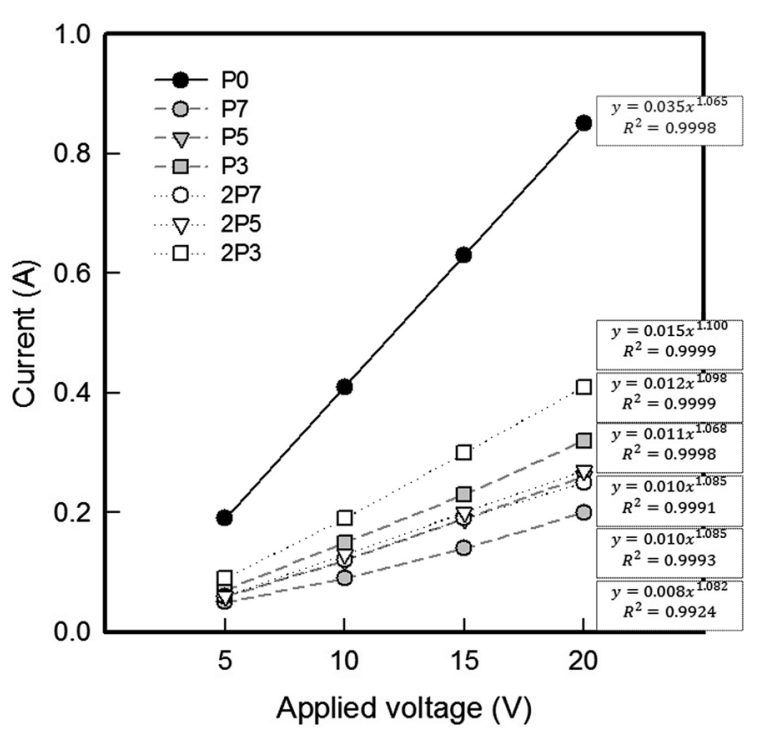

Fig. 3 Current-voltage characteristics of the CNF/PVDF-HFP composite coated on cotton fabrics with various circuit patterns 
current increased with increasing horizontal circuit lines, and further increased when the vertical line was added.

$$
I-V \text { characteristics can be expressed as }
$$

$$
I=K V^{\mathrm{n}}
$$

where $K$ is a constant and $\mathrm{n}$ is the exponent, which is determined from the slope of the curve in the $\log -\log$ scale. Ohm's law is fulfilled in the system at $n=1$ (Choudhury 2011; Srivastava and Mehra 2008).

Linear $I-V$ relationship at Ohm's law indicates that direct contact between the filler particles is the dominant conduction mechanism. However, the tunneling mechanism is the dominant mechanism for composites characterized by a power law $I-V$ relation (Choudhury 2011). The nonlinear behavior in I-V curves has a value of $n>1$. It represents nonlinear conduction due to tunneling of charge carriers (Srivastava and Mehra 2008).

In a sample coated with a concentration of $16 \mathrm{wt} \%$ CNF/PVDF-HFP composite solution, the sheet resistance value of samples with various circuit patterns was $\mathrm{P} 3<2 \mathrm{P} 3<$ $\mathrm{P} 5<2 \mathrm{P} 5<\mathrm{P} 7<2 \mathrm{P} 7<\mathrm{P} 0$. The power-law exponent values of the CNF/PVDF-HFP composite coated on cotton fabric with various circuit patterns are indicated in Table 1. All the samples satisfy $\mathrm{n}>1$ and thus it is considered to follow tunneling conduction.

\section{Electrical heating properties of CNF/PVDF-HFP composite coated on cotton fabrics with various circuit patterns}

IR thermal images of the surface temperatures of samples with various circuit patterns are shown in Fig. 4. The surface temperature of each sample was measured after various voltages from 5 to $20 \mathrm{~V}$ were applied for $90 \mathrm{~s}$. When a voltage of $5 \mathrm{~V}$ was applied, the temperature difference before and after the applied voltage showed a negligible value to $\pm 2.2{ }^{\circ} \mathrm{C}$. The surface temperature of P0 was $38.4 \pm 2.3,56.9 \pm 3.1$ and $76.9 \pm 6.4{ }^{\circ} \mathrm{C}$ with voltages of 10,15 , and $20 \mathrm{~V}$ applied, respectively. And the surface temperatures of P7, P5, P3 with $10 \mathrm{~V}$ voltage applied were $31.3 \pm 1.6,31.3 \pm 1.5$ and $33.4 \pm 2.1{ }^{\circ} \mathrm{C}$, respectively. At an applied voltage of $15 \mathrm{~V}$, the surface temperatures of P7, P5, P3 were $41.7 \pm 3.6,41.7 \pm 4.6$ and $48.9 \pm 5.2^{\circ} \mathrm{C}$, respectively. When $20 \mathrm{~V}$ was applied to P7, P5 and P3, they reached $60.6 \pm 8.5,58.4 \pm 8.7$ and $71.8 \pm 9.0{ }^{\circ} \mathrm{C}$, respectively. The P0 was the best in terms of the electric heating performance, but non-uniform heat distribution was shown as the result of the previous study (Kang and Lee 2015). However, IR thermal images of fabric heating elements with various circuit patterns coated with carbon nanocomposite showed that the heating temperature was lower than that of the P0, but the coating was more uniform.

The resultant surface temperatures of 2P7, 2P5 and $2 \mathrm{P} 3$ were $31.9 \pm 3.7,32.0 \pm 5.1$ and $35.2 \pm 2.8{ }^{\circ} \mathrm{C}$, respectively with an applied voltage of $10 \mathrm{~V}$. At an applied voltage of $15 \mathrm{~V}$, the surface temperatures of $2 \mathrm{P} 7,2 \mathrm{P} 5$ and $2 \mathrm{P} 3$ were $44.6 \pm 9.2,44.7 \pm 7.2$ and $46.9 \pm 5.1{ }^{\circ} \mathrm{C}$, respectively. The surface temperatures of $2 \mathrm{P} 7,2 \mathrm{P} 5,2 \mathrm{P} 3$ with an applied voltage of $20 \mathrm{~V}$ were $63.5 \pm 9.1,62.0 \pm 9.1$ and $75.7 \pm 7.7{ }^{\circ} \mathrm{C}$, respectively. The circuit with the added vertical line showed a similar trend and a slightly higher surface temperature than P7, P5, and P3. The surface resistances of 2P7, 2P5 and 2P3 were found to be slightly higher than those of P7, P5 and P3. 


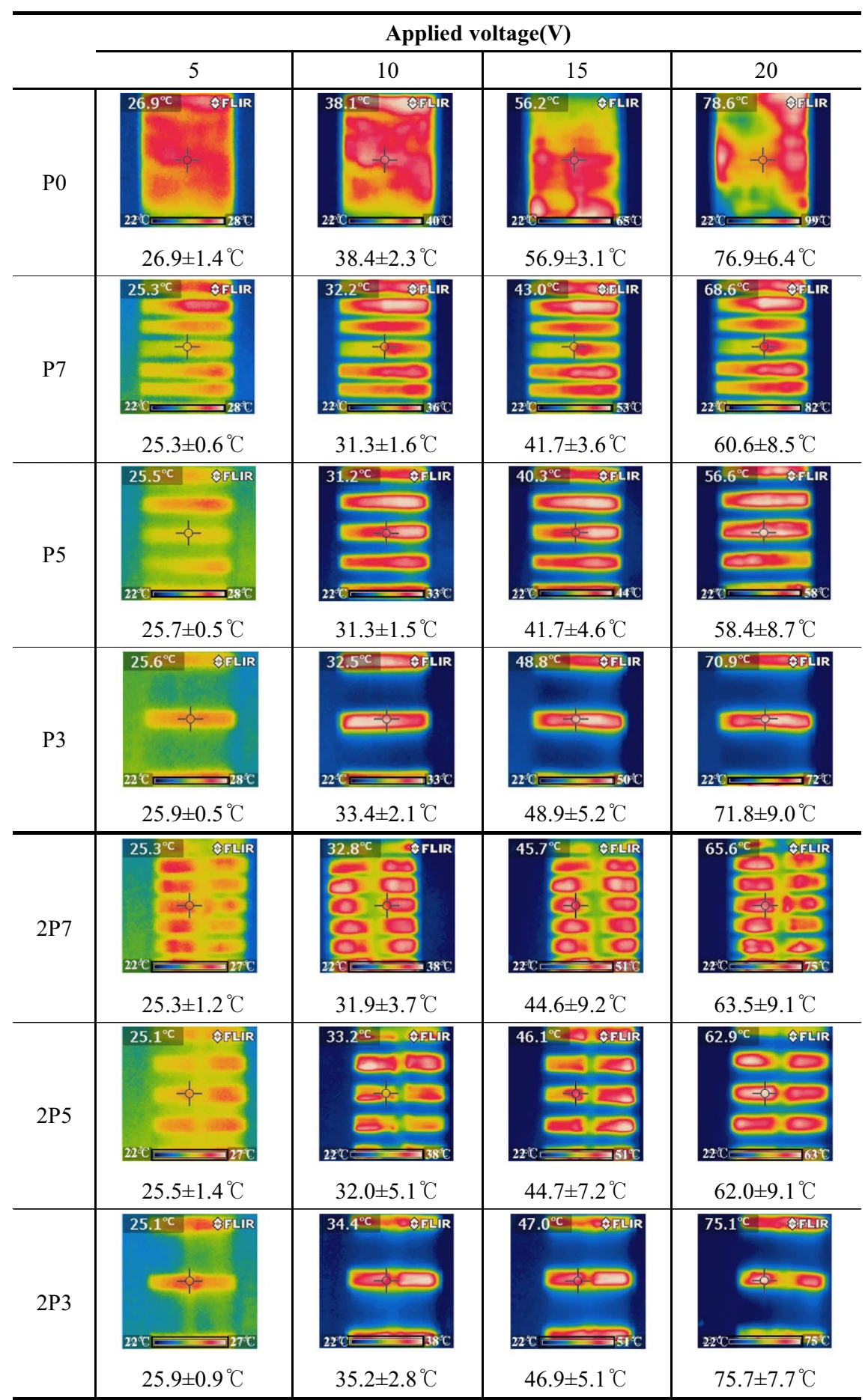

Fig. 4 IR thermal image of surface temperatures at various applied voltages of the CNF/PVDF-HFP composite coated on cotton fabrics with various circuit patterns

Kang and Lee (2015) reported on the electrical heating property of a fabric heating element with CNF nanocomposite coated on nylon fabric. A fabric heating element with carbon nanofiber composite was prepared in the size of $12 \times 12 \mathrm{~cm}$. The surface 
temperature indicated that the fabric heating element with $16 \mathrm{wt} \% \mathrm{CNF} / \mathrm{PVDF}-\mathrm{HFP}$ composite at $20 \mathrm{~V}$ was up to $89.1{ }^{\circ} \mathrm{C}$, but fluctuations were present. Ilanchezhiyan et al. (2015) studied electrical heating properties with CNT coated cotton fabrics for flexible/ wearable heating applications. CNT based cotton heaters were considered with short and long dimensions $(1 \times 2$ and $2 \times 4 \mathrm{~cm})$. For the $\mathrm{CNT}$ based cotton heater with short dimensions, the steady-state temperature at $20 \mathrm{~V}$ reached $55.0^{\circ} \mathrm{C}$, and for the one with long dimensions it was up to $35^{\circ} \mathrm{C}$. In this study, when a voltage of $20 \mathrm{~V}$ was applied, the CNF/PVDF-HFP composite coated on a cotton fabric with various circuit patterns showed a surface temperature of more than $60{ }^{\circ} \mathrm{C}$. In particular, P3 and $2 \mathrm{P} 3$ presented a uniform heating distribution of the surface temperature of $71.7 \pm 9.0$ and $75.7 \pm 7.7^{\circ} \mathrm{C}$ at an applied voltage of $20 \mathrm{~V}$. Thus, it was confirmed that the CNF/PVDF-HFP composite coated on a cotton fabric with decreasing conductive lines exhibited an excellent electrical heating property, and the use of a smaller amount of the CNF/PVDF-HFP composite than that of the plane fabric heating element can help achieve a reduction in cost.

Joule's law (Jee et al. 2013) also states that the power of heating generated by an electrical conductor is proportional to the product of its resistance and the square of the current. Thus, the surface resistance value of the patterns with added vertical circuit lines was larger than that of the patterns with horizontal circuit lines, and the surface temperature of samples was improved due to the resistance heat generation.

The current-dependent temperature of CNF/PVDF-HFP composite coated cotton fabric with P0, P3, and 2P3 is indicated in Fig. 5. The $\mathrm{R}^{2}$ values were 0.9664, 0.9524 and 0.9703 for the P0, P3 and 2P3, respectively. And the temperature-current characteristic indicated a tendency toward linear increases with increased current. As shown in Figs. 4 and 5 , if the voltage was increased there was an increase in the current, and accordingly, there was an increase in the surface temperature. As per Joule's law, the power is

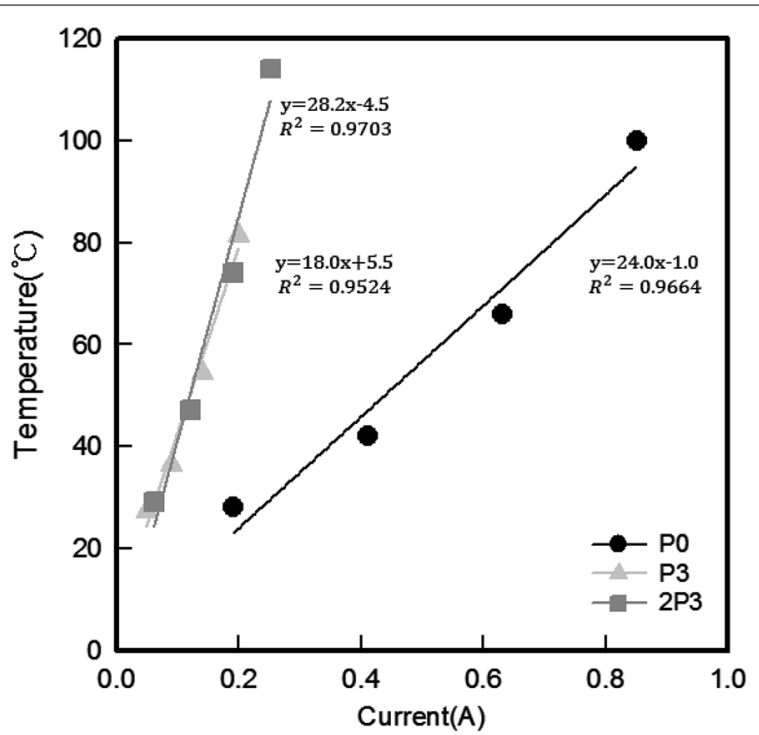

Fig. 5 Current-dependent temperature of CNF/PVDF-HFP composite coated cotton fabrics with various circuit patterns 
proportional to the square of the current, so the surface temperature increases proportionally as the current increases.

\section{Mechanical properties of CNF/PVDF-HFP composite coated cotton fabrics with various circuit patterns}

The mechanical properties of CNF/PVDF-HFP composite-coated cotton fabric with various circuit patterns are indicated in Table 1 . The tensile strength of uncoated cotton fabric was indicated as $7.33 \pm 0.26 \mathrm{~N}, \mathrm{P} 0$ was $10.10 \pm 0.15 \mathrm{~N}$. The results showed that the CNF/PVDF-HFP coated on cotton fabrics had higher tensile strength than the uncoated cotton fabric. Comparing the various patterns, the tensile strengths of P7, P5, and P3 were $8.31 \pm 0.09,8.25 \pm 0.40$, and $7.98 \pm 0.39 \mathrm{~N}$, respectively; for $2 \mathrm{P} 7,2 \mathrm{P} 5$, and $2 \mathrm{P} 3$ it was shown as $8.91 \pm 0.33,8.40 \pm 0.18$, and $8.28 \pm 0.58 \mathrm{~N}$, respectively. It is confirmed that the ultimate strength of carbon nanocomposite coated on cotton fabrics tends to be similar. The tensile strength of $2 \mathrm{P} 7,2 \mathrm{P} 5$, and $2 \mathrm{P} 3$ was slightly larger than that of $\mathrm{P}$, $\mathrm{P} 5$, and $\mathrm{P} 3$, indicating that the tensile strength increases as the number of lines coated with the CNF/PVDF-HFP composite increases. And the elongation of uncoated cotton fabric was $4.76 \pm 2.83 \%$ and $\mathrm{P} 0$ was $13.48 \pm 1.20 \%$, which was about 3 times increased. Comparing it by pattern, P7, P5 and P3 are 14.24 $\pm 1.44,14.08 \pm 0.82$ and $12.08 \pm 1.24 \%$ respectively, and 2P7, 2P5 and 2P3 were $15.28 \pm 0.24,15.08 \pm 0.69$ and $14.86 \pm 1.07 \%$, respectively. The elongation tended to be better when CNF/PVDF-HFP was coated than for uncoated cotton fabric, and 2P7, 2P5, and 2P3 were more increased than that of $\mathrm{P} 0$.

Generally, when the tensile strength is large, the elongation shows a small value. It is reported that when conductive nanoparticles such as CNT and graphite are well-dispersed in polymer matrix, it can enhance the inherent mechanical properties of polymeric materials (Coleman et al. 2006). In this study, the tensile strength and elongation of patterns of added vertical circuit lines, which had a large area coated with conductive composite solution, showed a large value. Therefore, it was confirmed that the highest work of rupture was $2 \mathrm{P7}$ and as the number of circuit pattern lines coated with a CNF/ PVDF-HFP composite decreased, it became a more flexible fabric heating element than plane fabric heating elements.

\section{Water repellent properties of CNF/PVDF-HFP composite coated cotton fabrics with various circuit patterns}

Contact angle images of CNF/PVDF-HFP composite coated cotton fabrics with various patterns are shown in Fig. 6 . To enhance the water repellent properties of carbon-based materials, studies have focused on increasing the surface roughness by introducing a geometric surface area (Meng and Park 2014). The contact angle value of the uncoated cotton fabric was indicated as $90.24^{\circ}$ and the cotton fabric coated with conductive composite solution was presented $99.93^{\circ}$. This result shows that when coated with a conductive composite solution, contact angle is increased by about $10^{\circ}$. Therefore, this shows that the contact angle was improved because the CNF formed a rough surface and introduced a geometric surface area. 


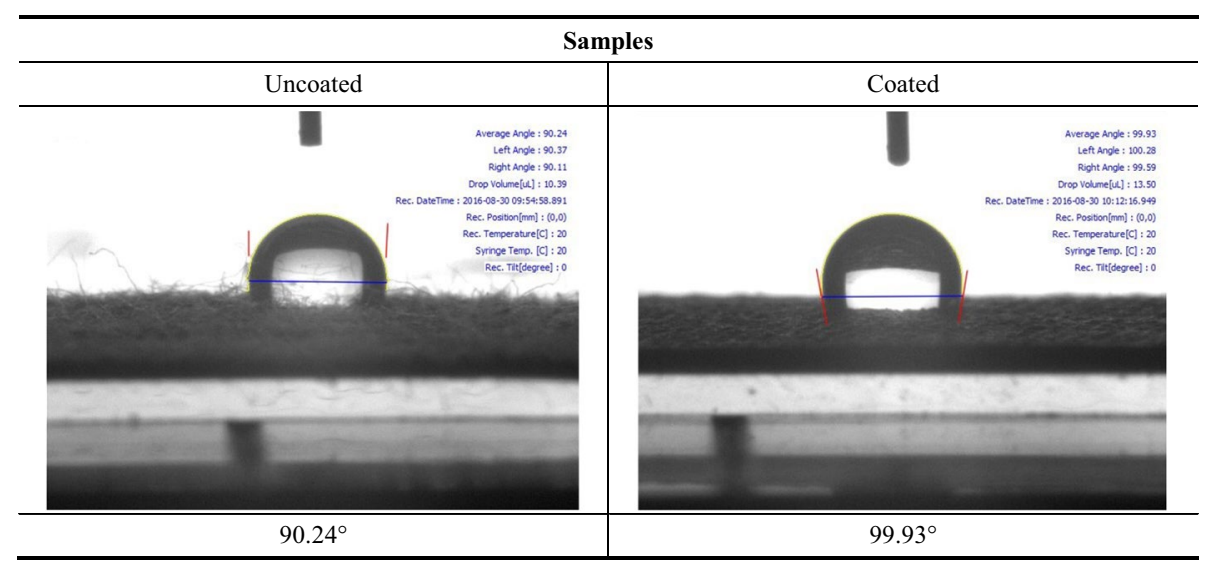

Fig. 6 Contact angle images of CNF/PVDF-HFP composite coated cotton fabrics

\section{Conclusion}

The purpose of this study was to develop fabric heating elements using CNF/PVDF-HFP composite coated cotton fabric with various circuit patterns with the aim of providing low cost, flexible, light, and uniform heating performance compared to conventional fabric heating elements. We prepared a carbon nanocomposite with electrical properties and it was coated cotton fabric with two types of circuit patterns. The sample code of P0 designates a reference sample, while P3, P5 and P7 were used when the number of horizontal lines was 3,5 , and 7, respectively; patterns in which a vertical line was added to the horizontal lines were named $2 \mathrm{P} 3,2 \mathrm{P} 5$, and $2 \mathrm{P} 7$, respectively. The surface resistivity values ranged from $1.01 \times 10^{3}$ to $1.65 \times 10^{3} \Omega / \mathrm{sq}$, and it was thus confirmed that the samples with various circuit patterns exhibit excellent electrical characteristics. The resistances of P3 and 2P3 were lower than those of fabric heaters with 5 and 7 lines, and it is thus presented that the effect of the resistance is less affected by the decrease in the number of lines. Comparing patterns, P7, P5 and P3 showed slightly lower resistances than $2 \mathrm{P} 7,2 \mathrm{P} 5$ and $2 \mathrm{P} 3$, indicating that the line in the vertical direction slightly increased the resistance. For electrical heating temperature, P7, P5 and P3 showed more uniform heating performance than $\mathrm{P} 0$ and the circuit with the added vertical line had a higher surface temperature than $\mathrm{P} 7, \mathrm{P} 5$, and $\mathrm{P} 3$ in terms of joule heating. $2 \mathrm{P} 3$ had the best heating performance, and the surface temperature was similar to $\mathrm{P} 0$ at about $76{ }^{\circ} \mathrm{C}$. In terms of mechanical properties and water repellency, it was confirmed that the coated fabrics had higher values compared to the uncoated fabric. Therefore, we confirmed that the electrical heating performance of the fabric heating element coated with carbon nanocomposite in three lines is improved compared to that of the plane fabric heating element, and it is also confirmed that it is more economical, flexible and lightweight than the conventional products because of its use of a smaller amount of carbon nanocomposite. Thus, it is suitable for use as a functional material for electric heating. Fabric heating elements that employ a CNF/PVDF-HFP composite with various circuit patterns have potential applicability in extreme work environments, for active winter sports, cold military training, and wet suits that must maintain body temperature in water. 


\section{Authors' contributions}

SL conceived the work and HK prepared the samples and performed the experiments. HK and SL are participated in the sequence alignment and drafted the manuscript. Both authors read and approved the final manuscript.

\section{Author details}

${ }^{1}$ Department of Fashion and Textiles, Dong-A University, Busan 49315, Republic of Korea. ${ }^{2}$ Department of Fashion Design, Dong-A University, Busan 49315, Republic of Korea.

\section{Acknowledgements}

This research was part of a master's thesis. This research was supported by Basic Science Research Program through the National Research of Korea (NRF) funded by the Ministry of Education, Science and Technology (No. NRF-2014R1A1A2057445).

\section{Competing interests}

The authors declare that they have no competing interests.

\section{Ethics approval and consent to participate}

Not applicable.

Received: 17 May 2017 Accepted: 16 November 2017

Published online: 28 March 2018

\section{References}

Åkerfeldt, M., Nilsson, E., Gillgard, P., \& Walkenström, P. (2014). Textile piezoelectric sensors—melt spun bi-component poly(vinylidene fluoride) fibres with conductive cores and poly(3,4-ethylene diocythiophene)-poly(styrene sulfonate) coating as the outer electrode. Fashion and Textiles, 1, 1-17. https://doi.org/10.1186/s40691-014-0013-6.

Al-Saleh, M. H., \& Sundararaj, U. (2009). A review of vapor grown carbon nanofiber/polymer conductive composites. Carbon, 47, 2-22. https://doi.org/10.1016/j.carbon.2008.09.039.

Asghar, A., Ahmad, M. R., \& Yahya, M. F. (2016). Effects of metal filament's alignment on tensile and electrical properties of conductive hybrid cover yarns. Fashion and Textiles, 3, 1-24. https://doi.org/10.1186/s40691-015-0055-4.

Choudhury, A. (2011). Synthesis and characterization of poly(o-toludine)/functionalized multi-walled carbon nanotubes nanocomposites with improved electrical conductivity. Materials Chemistry and Physics, 130, 231-236. https://doi. org/10.1016/j.matchemphys.2011.06.034.

Cipriano, B. H., Kota, A. K., Gershon, A. L., Laskowski, C. J., Kashiwagi, T., Bruck, H. A., et al. (2008). Conductivity enhancement of carbon nanotube and nanofiber-based polymer nanocomposites by melt annealing. Polymer, 49 , 4846-4851. https://doi.org/10.1016/j.polymer.2008.08.057.

Coleman, J. N., Khan, U., Blau, W. J., \& Gun'ko, Y. K. (2006). Small but strong: a review of the mechanical properties of carbon nanotube-polymer composites. Carbon, 44, 1624-1652.

Das, A., Schutzius, T. M., Bayer, I. S., \& Megaridis, C. M. (2012). Superoleophobic and conductive carbon nanofiber/fluoropolymer composite films. Carbon, 50, 1346-1354. https://doi.org/10.1016/j.carbon.2011.11.006.

Ilanchezhiyan, P., Zhkirov, A. S., Mohan Kumar, G., Yuldashev, Sh U, Cho, H. D., Kang, T. W., et al. (2015). Highly efficient CNT functionalized cotton fabrics for flexible/wearable heating applications. RSC Advances, 5, 10697-10702. https://doi. org/10.1039/C4RA10667A.

Jee, M. H., Lee, J. H., Lee, I. S., \& Baik, D. H. (2013). Electrical properties and heating performance of polyurethane hybrid nanocomposite films containing graphite and MWNTs. Textile Science and Engineering, 50, 108-114. https://doi. org/10.12772/TSE.2013.50.108

Kang, H. S., \& Lee, S. H. (2015). Preparation and characterization of carbon nanofiber composite coated fabric-heating elements. Journal of the Korean Society of Clothing and Textiles, 39, 247-256. https://doi.org/10.5850/jksct.2015.39.2.247.

Lee, S. H. (2011). Mechanical and electrical properties of nonwoven coated with CNFs/PVDF-HFP composite. Journal of the Korean Society for Clothing Industry, 13, 279-284.

Lee, S. H. (2012). Physical properties of silk fabrics coated by carbon nanofibers/poly(vinylidenefluoride-hexafloropropylene) composites. Textile Science and Engineering, 49, 119-125. https://doi.org/10.12772/TSE.2012.49.2.119

Meng, L. Y., \& Park, S. J. (2014). Superhydrophobic carbon-based materials: a review of synthesis, structure, and application. Carbon Letters, 15, 89-104. https://doi.org/10.5714/cl.2014.15.2.089.

Pahalagedara, L. R., Siriwardane, I. W. Tissera, N. D., Wijesena, R. N., \& Silva, K. M. N. (2017). Carbon black functionalized stretchable conductive fabrics for wearable heating applications. RSC Advances, 7, 19174-19180. https://doi. org/10.1039/c7ra02184d.

Park, J. Y., \& Lee, J. D. (2015). Electrical properties of carbon black composites for flexible fiber heating element. Journal of Koran Oil Chemists Society, 32, 405-411. https://doi.org/10.12925/jkocs.2015.32.3.405.

Park, H. K., Kim, S. M., Lee, J. S., Park, J. H., Hong, Y. K., Hong, C. H., \& Kim, K. K. (2015). Flexible plane heater: graphite and carbon nanotube hybrid nanocomposite. Synthetic Metals, 203, 127-134. https://doi.org/10.1016/j. synthmet.2015.02.015

Roh, J. S., \& Kim, S. (2016). All-fabric intelligent temperature regulation system for smart clothing application. Journal of intelligent materials systems and structures, 27, 1165-1175. https://doi.org/10.1177/1045389x15586901.

Srivastava, N. K., \& Mehra, R. M. (2008). Study of structural, electrical, and dielectric properties of polystyrene/foliated graphite nanocomposite developed via in situ polymerization. Journal of Applied Polymer Science, 109, 3991-3999.

Stempien, Z., Rybicki, E., Rybicki, T., \& Lesnikowski, J. (2016) Inkjet-printing deposition of silver electro-conductive layers on textile substrates at low sintering temperature by using an aqueous silver ions-containing ink for textronic applications. Sensors and Actuators B 224, 714-725. https://doi.org/10.1016/j.snb.2015.10.074. 
Tian, M., Du, M., Qu, L., Zhang, K., Li, H., Zhu, S., et al. (2016). Conductive reduced graphene oxide/MnO 2 carbonized cotton fabrics with enhanced cotton fabrics with enhanced electro -chemical, -heating, and -mechanical properties. Journal of Power Sources, 326, 428-437. https://doi.org/10.1016/j.jpowsour.2016.07.028.

Wang, H., Yi, S. I., Pu, X., \& Yu, C. (2015). Simultaneously improving electrical conductivity and thermopower of polyaniline composite by utilizing carbon nanotubes as high mobility conduits. ACS Applied Material Interfaces, 7, 9589-9597. https://doi.org/10.1021/acsami.5b01149.

Wang, R., \& Ruan, H. (2016). Synthesis of copper nanowires and its application to flexible transparent electrod. Journal of Alloys and Compounds, 656, 936-943. https://doi.org/10.1016/j.jallcom.2015.09.279.

Wang, Y., Jiang, H., Tao, Y., Mei, T., Liu, Q., Liu, K., et al. (2016a). Polypyrrole/poly(vinyl alcohol-co-ethylene) nanofiber composites on polyethylene terephthalate substrate as flexible electric heating elements. Composites: Part A, 81, 234-242. https://doi.org/10.1016/j.compositesa.2015.11.011.

Wang, Z., Wang, W., Jiang, Z., \& Yu, D. (2016b). Low temperature sintering nano-silver conductive ink printed on cotton fabric as printed electronis. Progress in Oraganic Coatings, 101, 604-611. https://doi.org/10.1016/j. porgcoat.2016.08.019.

\section{Submit your manuscript to a SpringerOpen ${ }^{\circ}$} journal and benefit from:

- Convenient online submission

Rigorous peer review

Open access: articles freely available online

- High visibility within the field

Retaining the copyright to your article

Submit your next manuscript at $\boldsymbol{\Delta}$ springeropen.com 